\title{
Assessment of relationship between the use of cell phone and social networks and sleep quality in students of medical sciences: A cross-sectional study
}

\author{
JAVAD AMINI SAMAN ${ }^{1}$, ALI VALINEJADI ${ }^{2,3}$, SAEED MOHAMMADI ${ }^{1}$, \\ HASSANALI KARIMPOR ${ }^{1}$, MARYAM MIRZAEI ${ }^{4}$, RASOOL KAWYANNEJAD ${ }^{5, *}$
}

${ }^{1}$ Department of Anesthesiology, School of Medicine, Kermanshah University of Medical Sciences, Kermanshah, Iran

${ }^{2}$ Social Determinants of Health Research Center, Semnan University of Medical Sciences, Semnan, Iran

${ }^{3}$ Health Information Department, School of Allied Medical Sciences, Semnan University of Medical Sciences, Semnan, Iran

${ }^{4}$ Department of Epidemiology, School of Allied Medical Sciences, Kermanshah University of Medical Sciences, Kermanshah, Iran

${ }^{5}$ Department of Anesthesiology, School of Allied Medical Sciences, Kermanshah University of Medical Sciences, Kermanshah, Iran ${ }^{*}$ Corresponding author: Rasool Kawyannejad; Department of Anesthesiology, School of Allied Medical Sciences, Kermanshah University of Medical Sciences, Kermanshah 6719851351, Iran; Phone: +98 918 9699149; Fax: +98 833 8279697; E-mail: rasol_kavyan@yahoo.com

(Received: April 28, 2018; Revised manuscript received: May 8, 2018; Accepted: May 18, 2018)

\begin{abstract}
Introduction: Sleep quality is an essential aspect in human health and function. Considering high prevalence of using smartphones and social networks among students and their impact on sleep quality, this study was conducted to determine the relationship between the overuse of cell phone and addiction to social networks and students' sleep quality. Materials and methods: This cross-sectional study was conducted in Kermanshah University of Medical Sciences, Kermanshah, Iran in 2018. Using cluster sampling, 321 students from different disciplines were selected. Data gathering tools consisted of the questionnaire of Pittsburgh Sleep Quality Index (PSQI). Cell phone use and addiction to social networks were assessed using Cell Phone Overuse Scale and a researcher-made questionnaire, respectively. Data were analyzed using SPSS software (version 19) and Pearson's correlation test. Results: The mean total score of sleep quality in students was $6.58 \pm 1.05$. There was a positive and significant correlation between sleep quality and social networks addiction score $(p<0.05, r=0.5)$ and cell phone overuse $(p<0.05, r=0.44)$; this is an inverse correlation, because higher scores of the total PSQI denote a lower sleep quality and, in Cell Phone Overuse Scale, higher scores shows overuse. Conclusions: According to the findings of this study, there was a significant statistical relationship between the overuse of cell phone and social networks and students' sleep quality. In other words, students who have had overuse of cell phones had poorer sleep quality. Therefore, providing effective educational programs to improve the sleep quality in this group is essential.
\end{abstract}

Keywords: smartphone, cell phone use, behavior, addictive, social networking, students

\section{Introduction}

Social programs entitled Internet Networks provide an online connection for users to interact quickly and easily [1]. The Internet and cell phone transmit millions of messages, which affect the users' values, attitudes, and cultural identity, as well as the cultural and social systems of the society. The emergence of symbolic realities in cyberspace has provided the ground for establishing social networking. Such a space encompasses features like placelessness and timelessness, no limitation in civil law based on states, simultaneous availability, possessing cultural, religious, philosophical, and economic spaces, and also being free from physical and sexual identity [2].

Capabilities of cell phone addiction, such as mobile Internet and social networking applications, should not be overlooked. Communication is the main reason that users use cell phones and social networks, and people can communicate with each other in a little time, but this has led to the overuse, especially at an early age. A study by Jin-jian [3] found that $8.1 \%$ and $37.8 \%$ of the students were suffered from serious and mild mobile phone

This is an open-access article distributed under the terms of the Creative Commons Attribution-NonCommercial 4.0 International License, which permits unrestricted use, distribution, and reproduction in any medium for non-commercial purposes, provided the original author and source are credited, a link to the CC License is provided, and changes - if any - are indicated. 
addictions. In other study in Hong Kong, long hours of mobile phone use were correlated with short sleep duration and excessive daytime sleepiness [4].

Disorders such as anxiety, fatigue, sleep disturbances, confusion, abnormal insomnia, and digestive problems are common complications of using cell phone and social networks [5]; these disorders can affect the quality of general health and function of people.

Researches have shown that the overuse of cell phone was associated with increasing features of abnormal behavior patterns, such as staying awake overnight and messaging, and it brought about mental emotional dependency for the users [6-9].

In addition to that, the results of various studies showed that the use of cell phone and its applications caused disturbance in sleep and concentration and also led to physical and mental problems, such as fatigue and headache [10]. Sleep disorders increase the risk of physical and emotional problems that are common among adults and adolescents. Sleep is one of the physiological needs of every human being that is needed to improve a healthy life. Several factors affect the quality of sleep, but one of the factors that has been underestimated is the use of technologies and social networks. In recent years, health psychology has emphasized on coping strategies with technologies' complications and their side effects and has assessed physical and mental aspects of lifestyle status in dealing with these side effects. Cell phone is one of the most common technologies used to communicate with others [11]. This technology is more common in all social strata, especially among youngsters and students, and thus they are more exposed to the complications of cell phone and social networks. This is due to the fact that they are easily accessible, provide their users with security, and have a key role in social communication [12], thus attracting the attention of different social groups, including students [13]. Apart from the positive effects of mobile phones on productivity as well as convenience in academic and professional settings, they might cause Internet and mobile phone addiction if used excessively [14]. These complications may affect the physical and mental functions and also the user's social status. Loughran et al. [15] pointed out the harmful effects of electromagnetic field on the brain emitted from cell phone during the sleep time. Other researches have also shown that more exposure to cell phone overnight could affect the onset of melatonin secretion [16].

Since various studies have reported poor sleep quality of students who have overused the virtual networks, due to the importance of this issue and the prevalent use of cell phone and social networks among different people, especially among students, and also considering the effects of these networks on daily physiological and psychological functions, this study was conducted in the aim of investigating the relationship between overuse of cell phone and addiction to social networks and sleep quality among students of Kermanshah University of Medical Sciences (KUMS) in 2018.

\section{Materials and Methods}

This study was a cross-sectional study, which was approved by Ethics Committee of KUMS in 2018. It was conducted on 321 students of KUMS. The population of this study was the students of KUMS and a sample size of 5,000 undergraduate students in the first semester of 2018 was randomly determined using Morgan table. Through random and clustered method, 350 students were selected from undergraduate and post-graduate courses (Bachelor, Master, and PhD) in different schools including paramedical, medical, nursing, dentistry, health, and pharmacy colleges. Students' demographic data were recorded including age, gender, duration of cell phone use, duration of daily presence in social networks using cell phone, number of years of membership in social networks, and number of registered social networks. Entry criteria included being a second-year student or above, using smartphone and social networking applications, being an indigenous student of Kermanshah and not living in dormitories, and no history of mental illness, acute physical illness, and drug consumption (such as narcotics, sedatives, psychotropic drugs, and the brain stimulances) that could affect the variables.

Due to the problems of dormitories, long distance from home, and new environment for freshman students could affect the variables of the study, and in order to increase the accuracy and reliability of the study population, only second-year students and above and also indigenous students were selected. In this study, the main variables were cell phone overuse and social networks addiction, and in order to determine their relationship with sleep quality among the subjects, the Cell Phone Overuse Scale and Social Network Addiction Questionnaire consisting of 15 questions were used.

\section{Pittsburg Sleep Quality Index (PSQI)}

This questionnaire examines the attitude toward sleep quality in the past 4 weeks. It has seven component scores including subjective sleep quality, sleep latency, sleep duration, habitual sleep efficiency, sleep disturbances, use of sleeping medication, and daytime dysfunction. Each item is scored on a $0-3$ Likert scale. Then, the total PSQI score is calculated, ranging from 0 to 21 , where higher scores denote a lower sleep quality. The total score above 5 indicates a significant sleep disorder. It takes 5-10 min to complete [17]. Reliability and validity of this questionnaire in Iran was confirmed by Cronbach's $\alpha 0.77$ in the study by Moghaddam et al. [18] 


\section{Cell Phone Overuse Scale}

This questionnaire is designed based on the psychological index of the Diagnostic and Statistical Manual of Mental Disorders. It has 23 items and scoring is based on a 6-point Likert scale ( 1 - never, 2 - almost never, 3 - sometimes, 4 - often, 5 - almost always, and 6 - always). A score above 75 shows overuse, between 25 and 75 normal use, and below 25 low usage [19]. Validity and reliability of this questionnaire in Iran was confirmed by Cronbach's $\alpha$ 0.903 in the study by Golmohammadian et al. $[19,20]$

\section{Social Network Addiction Questionnaire}

It is a researcher-made questionnaire consists of 15 questions about knowing social networks (Facebook, Orkut, MySpace, Viber, LINE, Tango, WeChat, Telegram, WhatsApp, Instagram, Twitter, LinkedIn, YouTube, Status, etc.) and using them. The scoring is based on a 5-point Likert scale (from $5=$ always to $0=$ rarely). For designing this researcher-made questionnaire, various authentic scientific texts, similar studies, and experts' opinions in this field were used. Its validity was confirmed by five scientific board members and its reliability was 0.83 based on Cronbach's $\alpha$. Assessing and scoring were as follows: total score from 1 to 25 assumed as a normal user; the scores from 26 to 49 suggested that the user was about to get addicted to social networks and it was better to prevent this addiction; and scores from 50 to 75 considered that the user was addicted to social networks and he or she should think about the treatment as soon as possible.

The data were analyzed using SPSS (version 19) software. The data for quantitative and qualitative variables were reported with mean (standard deviation) and frequency (percentages), respectively. The Pearson's correlation test was used to investigate the relationship between overuse of cell phone, addiction to social networks, and the students' sleep quality. The significance level in this study was considered to be $p<0.05$.

Ethical approval was obtained from the Kermanshah University of Medical Ethics Committee (IR.KUMS. REC.1395.328).

\section{Results}

The mean age of the participants was $21.03 \pm 1.81$ years. Out of 321 subjects, $39.9 \%$ were male and the others were female. The daily time of cell phone use was $3.57 \pm$ $2.87 \mathrm{~h}$ and the daily time of active presence in social networks was $3.32 \pm 1.42 \mathrm{~h}$. Besides, the duration of being a member in social networks was $2.9 \pm 1.57$ years.

The highest membership rates in social networks were seen as follows: Telegram 92.83\%, Instagram 48.59\%, Facebook 38.31\%, LINE 32.08\%, Viber 28.66\%, Twitter $15.26 \%$, Tango $14.95 \%$, WeChat $12.46 \%$, WhatsApp 9.96\%, LinkedIn 9.56\%, YouTube 5.6\%, Status 4.67\%, and others $3.11 \%$.

The most common reasons for using social networks were having communication with friends (94.39\%), obtaining scientific information and news $(80.99 \%)$, entertaining and having fun $(71.65 \%)$, sharing movies and photos $(48.59 \%)$, being lonely $(34.26 \%)$, having activity in groups and channels $(26.66 \%)$, and others $(9.34 \%)$.

In the subjects, the mean time between going to bed and falling asleep was $20.49 \pm 14.9 \mathrm{~min}$. The actual sleep rate in the students was $58.8 \pm 1.05 \mathrm{~h}$. About $53.9 \%$ of students had poor sleep quality.

The relationship between variables of cell phone overuse, addiction to social networks, and sleep quality is shown in Table I.

According to the results of correlation test, there was a positive and significant correlation between sleep quality and social networks addiction score $(p<0.05, r=0.5)$ and cell phone overuse $(p<0.05, r=0.44)$; this is an inverse correlation, because higher scores of the total PSQI denote a lower sleep quality and, in Cell Phone Overuse Scale, higher scores shows overuse.

Women had significantly more addiction to mobile phones and social networks than men, respectively ( $p$ values of 0.04 and 0.004 ), but there was no significant difference in sleep quality $(p=0.06)$.

\section{Discussion}

The main objective of this study was to investigate the relationship between the overuse of cell phone and addiction to social networks and the sleep quality among students. According to the results, there was a significant relationship between the rate of social network use and the overuse of cell phone and sleep quality. In other words, by increasing the use of cell phone, the rate of sleep disorders increases. The results of this study are in consistent with the results of other similar studies, such as the study of Mohammadbeigi et al. [21] in students of

Table I Relationship between sleep quality and overuse of cell phone and addiction to social networks

\begin{tabular}{lccc} 
& & \multicolumn{2}{c}{ Sleep quality } \\
Main variables & Mean (SD) & Pearson's correlation coefficient & Significance level \\
Cell phone overuse & $51.96(18.55)$ & 0.44 & 0.001 \\
Social networks addiction & $30.79(10.57)$ & 0.50 & 0.001 \\
\hline
\end{tabular}

SD: standard deviation 
Qom University of Medical Sciences, which reported a direct and significant relationship. Besides, Majidaei et al. [22] found a positive and significant correlation between the overuse of cell phone and sleep quality in the students of Kharazmi University and Payame Noor University in Karaj city. Moreover, Wolniczak et al.'s [23] study suggested that students with addiction to Facebook suffered from sleep disorders more than other students.

"Telegram" application according to the results of our study, in Iran, due to the facilities, fast communications various programs, is most used among young people and other peoples.

In another study, Lemola et al. [24] related the overuse of mobile phones with sleep disorders. White et al. [25] also reported a significant relationship between mobile phone use and sleep quality.

Using these technologies in three different ways can lead to sleep disturbance: (1) The use of this technology straightly replaces sleep and leads to a reduction of sleep time; (2) During the use of this technology, the physiological, cognitive, and emotional consciousness increases; (3) Optical stimuli emitted from the screen can stimulate the retina and send signals to the hypothalamus, which disturbs the secretion of melatonin and delays in nightly rhythms resulting in insomnia and drowsiness [26-30].

Students who have abundant use of cell phone and other communication technologies are at high risk of developing psychological illnesses [31]. Since sleep is one of the important biological mechanisms in the mood adjustment, these users are exposed to high levels of restlessness, difficulty in concentrating, and reduction in energy and daily sleep time [22].

In this study, $53.9 \%$ of students had poor sleep quality. In other related national studies, it was seen that the prevalence of poor sleep quality was $39.8 \%$ among students of Mashhad University of Medical Sciences. It was also $40.6 \%$ in students of Zanjan University of Medical Sciences, $86.4 \%$ in students of Zanjan University of Medical Sciences during their final exams, and $43.1 \%$ in students of Urmia University of Medical Sciences [32-35].

In the aforementioned Iranian studies, there was no association between sleep disorders and factors affecting it, such as cell phones and social networks.

The use of social networks in Iran has suddenly spreaded over and over and includes all people of society. This is despite the fact that there is no culture of education and awareness in this area for young people.

The results of this study are similar to the results of international studies on the prevalence of poor sleep quality in students [36].

The results of cell phone usage suggested that most students used cell phone normally, and only $15.6 \%$ of students had cell phone overuse, while in Atadokht's [37] study, this rate was reported as $5.5 \%$ in the students of University of Mohaghegh Ardabili; in addition, it was reported as $10.7 \%$ in Mohammadbeigi's [21] study among students at Qom University of Medical Sciences.

In a study of students conducted in Switzerland, the rate of cell phone addiction was reported as $16.9 \%$ [38]. A study in India showed that $33.33 \%$ of adolescents had cell phone addiction [39]. Nehra et al. [40] reported cell phone addiction of adults with the same rate. One of the factors that increases this dependency is the hardware and the software features on the smartphones, because many of these features are used in the fields of information, education, entertainment, games, news, photography and video recording, communication, and job. Overuse of cell phone causes some kind of dependency and, in severe cases, becomes a routine for users. This dependency gradually becomes habituated and consequently, results in a kind of addiction [41, 42].

$\mathrm{Xu}$ et al. [43] stated that more than half of undergraduates who use social media experience poor sleep quality, which is consistent with this study. Using social media before bedtime influences on sleep quality in many aspects. Most of the potential impact of social media use on sleep quality seems to be during daytime. The study by $\mathrm{Xu}$ et al. [43] reported that a minority of people experience multiple arousals during sleep, poor memory, and depression.

This study is subjected to certain limitations in terms of cross-sectional nature of the study, which should be considered in the generalization of the results. These results are restricted to the students of KUMS and must be careful in generalizing the results to other universities and institutions. On the other hand, considering the nature of a cross-sectional study, it is recommended to conduct more elaborated longitudinal studies to confirm the causal relationships among the variables.

\section{Conclusions}

Given the results of this study and previous studies, and the relationship between the effects of using cell phone and social networks on the sleep quality in university students, it is needed to design fruitful educational programs to improve sleep quality in this group.

$$
\text { *** }
$$

Funding sources: All credits of this project (project number: 95313) were funded by Research and Technology Deputy of Kermanshah University of Medical Sciences in Iran.

Authors' contribution: All authors contributed to this project and article equally.

Conflict of interest: The authors declare no conflict of interest in relation to the work.

Acknowledgements: The authors would like to show their gratitude to the Research Deputy of Kermanshah University of Medical Sciences and all the students participated in this research. 


\section{References}

1. Shahghassemy A: Review on effect of virtual space fields on communication theories. Global Media J 2, 31-37 (2006)

2. Mohseni M 2002: Sociology of information society. Iran Didar Publication, Tehran, p. 31.

3. Jin-jian Z: Studying on the relationship among perceived stress, motivation of using mobile phone and mobile phone dependence of college students. Chin Health Serv Manag 2, 23 (2015)

4. Mak YW, Wu CS, Hui DW, Lam SP, Tse HY, Yu WY, Wong HT: Association between screen viewing duration and sleep duration, sleep quality, and excessive daytime sleepiness among adolescents in Hong Kong. Int J Environ Res Public Health 11, 11201-11219 (2014)

5. Hassanzadeh RA: Effect of sex, course and age on SMS addiction in student. Middle-East J Sci Res 10, 619-625 (2011)

6. Zermatten ABJ, Vandrlinden M, Dacremont M, Ceschi G: Does impulsivity relate to the perceived dependence on actual use of the mobile phone. Appl Cogn Psychol 21, 527-537 (2007)

7. Agarwal A, Deepinder F, Sharma KS, Ranga G, Li J: Effect of cell phone usage on semen analysis in men attending infertility clinic: An observational study. Fertil steril 89, 124-128 (2008)

8. Laru GI, Sanna J: Social pattern in mobile technology mediated collaboration among members of the professional distance education community. Educ Media Int 45, 17-32 (2008)

9. Zokaee M, Katibi F: Relationship of presence in cyberspace and modern identity, research in young Iranian Internet users. J Soc Sci 33, 34-37 (2012)

10. Mantegi M (2007): Parental guidance in children using communicational technology. Abed Publication, Tehran, pp. 220-222

11. Munezawa T, Kaneita Y, Osaki Y, Kanda H, Minowa M, Suzuki K, Higuchi S, Mori J, Yamamoto R, Ohida T: The association between use of mobile phones after lights out and sleep disturbances among Japanese adolescents: A nationwide cross-sectional survey. Sleep 34, 1013-1020 (2011)

12. Balakrishnan V, Raj RG: Exploring the relationship between urbanized Malaysian youth and their mobile phones: A quantitative approach. Telemat Inf 29, 263-272 (2012)

13. Dixit S, Shukla H, Bhagwat A, Bindal A, Goyal A, Zaidi AK, Shrivastava A: A study to evaluate mobile phone dependence among students of a medical college and associated hospital of central India. Indian J Community Med 35, 339-341 (2010)

14. Ahn S-Y, Kim Y-J: The influence of smart phone use and stress on quality of sleep among nursing students. Indian J Sci Technol $8(2015)$

15. Loughran SP, Wood AW, Barton JM, Croft RJ, Thompson B, Stough C: The effect of electromagnetic fields emitted by mobile phones on human sleep. Neuroreport 16, 1973-1976 (2005)

16. Wood AW, Loughran SP, Stough C: Does evening exposure to mobile phone radiation affect subsequent melatonin production? Int J Radiat Biol 82, 69-76 (2006)

17. Rush J (2000): Handbook of psychiatric measures. APA, Washington, DC.

18. Moghaddam JF, Nakhaee N, Sheibani V, Garrusi B, Amirkafi A: Reliability and validity of the Persian version of the Pittsburgh Sleep Quality Index (PSQI-P). Sleep Breath 16, 79-82 (2012)

19. Jenaro C, Flores N, Gomez VM, Gonzlez GF, Caballo C: Problematic Internet and cell-phone use. Psychological, behavioral, and health correlates. Addict Res Theory 15, 309-312 (2007)

20. Golmohammadian M, Yaseminejad P: Normalization, validation and reliability of COS in students. J New Find Psychol 13, 37-52 (2010)

21. Mohammadbeigi A, Absari R, Valizadeh F, Saadati M, Sharifimoghadam S, Ahmadi A, Mokhtarie M, Ansari H: Sleep quality in medical students; the impact of over-use of mobile cellphone and social networks. J Res Health Sci 16, 46-50 (2016)

22. Majidaei M, Pir-Einaladin S, Kasaee A: The role of cell-phone over use in anticipation of sleep quality, anxiety and depression among university students. J Educ Comm Health 2, 38-46 (2015)
23. Wolniczak I, Cáceres-DelAguila JA, Palma-Ardiles G, Arroyo KJ, Solís-Visscher R, Paredes-Yauri S, Mego-Aquije K, BernabeOrtiz A: Association between Facebook dependence and poor sleep quality: A study in a sample of undergraduate students in Peru. PLoS One 8, e59087 (2013)

24. Lemola S, Perkinson-Gloor N, Brand S, Dewald-Kaufmann JF, Grob A: Adolescents' electronic media use at night, sleep disturbance, and depressive symptoms in the smartphone age. J Youth Adolesc 44, 405-418 (2015)

25. White AG, Buboltz W, Igou F: Mobile phone use and sleep quality and length in college students. Int J Humanit Soc Sci 1, 51-58 (2011)

26. Cain N, Gradisar M: Electronic media use and sleep in school-aged children and adolescents: A review. Sleep Med 11, 735-742 (2010)

27. Chang AM, Aeschbach D, Duffy JF, Czeisler CA: Evening use of light-emitting eReaders negatively affects sleep, circadian timing, and next-morning alertness. Proc Natl Acad Sci U S A 112, 1232-1237 (2015)

28. Liu Z, Zhao Z: Effects of light interruption on sleep and viability of Drosophila melanogaster. PLoS One 9, el05678 (2014)

29. Mesquita G, Reimaeo R: Quality of sleep among university students: Effects of nighttime computer and television use. Arquivos de Neuro-Psiquiatria 68, 720-725 (2010)

30. Barion A, Zee PC: A clinical approach to circadian rhythm sleep disorders. Sleep Med 8, 566-577 (2007)

31. Yaseminejad P, Golmohammadian M, Yoosefi N: The study of the relationship between cell-phone use and general health in students. Knowl Res Appl Psychol 13, 60-72 (2012)

32. Rezaei Ardani A, Talaei A, Borhani Moghani M, Nejati R, Sabouri S, Solooti S, Hoseini SA: Assessment the rules of demographic variables and body mass index in sleep quality among medical students. J Fundam Ment Health 14, 132-139 (2012)

33. Aghajanloo A, Haririan H, Ghafourifard M, Bagheri H, Ebrahimi SM: Sleep quality of students during final exams in Zanjan University of Medical Sciences. Mod Care Sci Quart Birjand Nurs Midwifery Fac 8, 230-237 (2012)

34. Ghanei R, Hemmati Maslakpak M, Rezaei K, Baghi V, Makki B: Nursing student quality of sleep in dormitory of Urmia University of Medical Sciences. J Urmia Nurs Midwifery Fac 9, 277-282 (2011)

35. Ghoreishi SA, Aghajani AH: Sleep quality in Zanjan University Medical students. Tehran Univ Med J 66, 61-67 (2008)

36. Masquita G, Reimao R: Quality of sleep among university students: Effects of nighttime computer and television use. Arq Neuropsiquiatr 5, 720 (2010)

37. Atadokht A: The relationship of cell phone overuse with psychopathology of sleep habits and sleep disorders in university students. J Urmia Nurs Midwifery Fac 14, 136-144 (2016)

38. Haug S, Castro RP, Kwon M, Filler A, Kowatsch T, Schaub MP: Smartphone use and smartphone addiction among young people in Switzerland. J Behav Addict 4, 299-307 (2015)

39. Nikhita CS, Jadhav PR, Ajinkya SA: Prevalence of mobile phone dependence in secondary school adolescents. J Clin Diagn Res 9, VC06-VC09 (2015)

40. Nehra R, Kate N, Grover S, Khehra N, Basu D: Does the excessive use of mobile phones in young adults reflect an emerging behavioral addiction? J Postgrad Med Educ Res 46, 177-182 (2012)

41. Kamibeppu K, Sugiura H: Impact of the mobile phone on junior high-school students' friendships in the Tokyo metropolitan area. Cyberpsychol Behav 8, 121-130 (2005)

42. Billieux J, Van der Linden M, d'Acremont M, Ceschi G, Zermatten A: Does impulsivity relate to perceived dependence on and actual use of the mobile phone? Appl Cognitive Psychol 21, 527-537 (2007)

43. Xu XL, Zhu RZ, Sharma M, Zhao Y: The influence of social media on sleep quality: A study of undergraduate students in Chongqing, China. J Nurs Care 4, 253 (2015) 